\title{
Consanguinity, inbreeding coefficient, fertility and birth-outcome in population of Okara district, Pakistan
}

\author{
Aqeela Nawaz', \\ Muhammad Zaman' ${ }^{2}$ Sajid Malik
}

\begin{abstract}
Objectives: This study was aimed to illustrate the determents of consanguinity and inbreeding coefficient- $F$ (ICF) in the population of Okara district of Pakistan and to elucidate the impact of consanguinity on fertility and birth outcome.

Methods: Through a cross-sectional sampling design, 1,521 married women were recruited from Okara district during 2016-2017. Data on demographic variables, marital union types, subject's fertility, and reproductive outcome, were gathered in face-to-face interviews. Descriptive statistics and multivariable logistic regression were employed.

Results: The prevalence of consanguineous unions (CU) was calculated to be $61 \%$ yielding ICF $=0.0356$. Multivariable regression analyses revealed that six variables including younger age at marriage, joint family structure, caste-system of spouse, exchange marriage, matrimonial distance, and parental consanguinity, were significant predictors of consanguinity. The women having CU had significantly higher mean fertility, mean live-births and mean live-born sons compared with subjects having non-consanguineous unions (NCU). However, there were no significant differences in the average mortalities, i.e., prenatal, postnatal and $<5$ years, between the mothers with CU and NCU.

Conclusion: The prevalence of consanguineous unions (CU) in Okara district is quite high like other inbred populations of Pakistan. The striking findings of this study are the higher mean fertility and mean livebirths in women with CU. The likely reasons underlying this phenomenon have been discussed.
\end{abstract}

KEYWORDS: Epidemiology, Demography, Consanguineous unions, Fertility outcome, Reproductive outcome, Sex ratio, Child morality, Child morbidity.

doi: https://doi.org/10.12669/pjms.37.3.2263

How to cite this:

Nawaz A, Zaman M, Malik S. Consanguinity, inbreeding coefficient, fertility and birth-outcome in population of Okara district, Pakistan. Pak J Med Sci. 2021;37(3):770-775. doi: https://doi.org/10.12669/pjms.37.3.2263

This is an Open Access article distributed under the terms of the Creative Commons Attribution License (http://creativecommons.org/licenses/by/3.0), which permits unrestricted use, distribution, and reproduction in any medium, provided the original work is properly cited.

1. $\quad$ Aqeela Nawaz, M.Phil. Human Genetics Program, Department of Zoology,

2. Muhammad Zaman, PhD. Department of Sociology,

3. Sajid Malik, PhD.

Human Genetics Program, Department of Zoology,

1-3: Quaid-i-Azam University,

Islamabad, Pakistan.

Correspondence:

Dr. Sajid Malik,

Human Genetics Program,

Department of Zoology,

Quaid-i-Azam University,

Islamabad, Pakistan.

E-mail: malik@qau.edu.pk

* Received for Publication:

* Revision Received:

* Revision Accepted:
January 27,2020

January 13, 2021

January 25, 2021

\section{INTRODUCTION}

Pakistan is an interesting ground for the study of various aspects of demography like assortative mating and consanguinity. ${ }^{1}$ The pattern of marital alignments and consanguinity is useful in elucidating the socio-biological structure of populations and assessing health and disease patterns. ${ }^{2,3}$ Elevated consanguinity has been reported to be associated with higher incidences of congenital anomalies, child mortality and adult morbidity, and decreased fertility. ${ }^{3-6}$

Consanguinity is a deeply rooted social and cultural trend in Pakistan. ${ }^{7}$ The major cause for an advantage of consanguineous unions (CU) is socio- 
cultural instead of economic benefits. A review of the literature on this subject revealed that despite certain generalizations the factors underlying consanguinity vary in different populations of Pakistan. ${ }^{2,7-9}$

The world population has been divided into four broad categories based on the prevalence of CU, i.e., $<1 \%, 1-10 \%, 10-50 \%$, and unknown. ${ }^{5}$ Pakistan falls into the third category where an overall high prevalence of consanguinity has been reported. . $^{50,11}$ Here, consanguinity has been studied primarily in upper Punjab and few populations of Khyber Pakhtunkhwa province. ${ }^{2,8,9,11}$ The pattern of consanguinity remains unknown for most of the Southern and Western regions which may comprise populations with distinct breeding structures. Hence, the categorization of Pakistani populations on the basis of consanguinity level is not yet possible. To this end, this study was aimed at the determination of consanguinity, fertility and birth-outcome in the population of Okara district of Punjab, Pakistan.

\section{METHODS}

Study Population: Okara district is situated in the South-East of Punjab, Pakistan. According to the 2017 census, the district's population was three million and $>80 \%$ was rural. The district comprises three tehsils namely Okara, Depalpur and Renala Khurd. ${ }^{12}$ The most prominent caste-systems are Arain, Bhatti, Jutt, Kharal, Khokhar/Malik, Kamyanay, Muslim-Rajput, and Rajput.

Sampling Strategy and Definitions: Through a cross-sectional sampling design, ever-married females were enrolled during 2016-2017. There were 19 different sampling sites encompassing main towns/villages of the district. The fieldwork was coordinated by the lady-health-visitors and paramedical staff. This study was approved by the ethical review committee of Quaid-i-Azam University (DAS/13-651; June 3, 2013).

After a verbal consent approval, the data were collected on a structured proforma. Information on marital union types and demographic/household parameters (including tehsil, rural/urban residence, subject/spouse age, subject/spouse literacy, occupation of subject/spouse, family structure, household type, exchange marriage, subject's age at marriage, matrimonial distance, and parental consanguinity) was collected (as described elsewhere)., ${ }^{2,8}$ Inbreeding coefficient-F (ICF) was calculated from the proportion of $\mathrm{CU}$ types in total marriages in a respective category. ${ }^{5,7}$
Data were also gathered on fertility, gap in the first pregnancy, live-births, and reproductive loss, i.e., neonatal, postnatal and $\leq 5$ years mortality. Descriptive summaries were generated and the significance of deviation from random distribution was checked at $p<0.05$. Multivariable analyses were carried out through logistic regression, performed in various tiers where consanguinity was put as a dichotomous variable and the dependent variables were included in the model step-by-step.

\section{RESULTS}

A total of 1,521 married women ranging in age from 15-to-80 years were enrolled. A total of 933 $(61.3 \%)$ subjects had $\mathrm{CU}$, yielding $\mathrm{ICF}=0.0356$ (Table-I). First cousin (FC) unions were the highest in proportion and accounted for $50.2 \%(n=763)$ of the total sample. Double first cousin, first-cousinonce-removed, and second cousin marriages were $1.4 \%, 6.6 \%$, and $3.2 \%$, respectively. The unions among second-cousin-once-removed, distantly related and non-related were $0.1 \%, 28.1 \%$ and $10.4 \%$, respectively.

Contingency test statistics showed that the $\mathrm{CU}$ were significantly associated with variables like rural/urban residence (higher in subjects from rural background; OR: 1.37), literacy of subjects and spouses (higher in illiterates; OR: 1.13 and 1.11 , respectively), occupational status of subjects and spouses, joint family structure (OR: 1.80), household type (higher in paternal type; OR: 1.59), exchange marriage (OR: 2.51), age at marriage (higher in younger age; OR: 1.38), matrimonial distance (higher in less distance; OR: 1.87), and parental consanguinity (OR: 1.76). The differences in the distribution of $\mathrm{CU}$ and NCU appeared statistically not significant with respect to tehsils, mother tongue, caste-system of subjects/spouses, current age of subject/spouse, and marriage year (data not shown).

In logistic regression, six variables emerged as significant predictors of consanguinity, i.e., caste-system of spouse, age at marriage, exchange marriage, matrimonial distance, family type, and parental consanguinity, while the overall model was highly significant (Table-II). Temporal analyses across 10 years intervals revealed that the rate of consanguinity fluctuated between $59 \%$-to- $63 \%$ and any decreasing or increasing trend over the years was not conspicuous (Chi-test for trend; $\mathrm{p}=0.627$ ).

Ever pregnant women were 1,958 (90.9\%) (Table-III). The subjects having CU had significantly higher mean fertility than subjects 
Table-I: Consanguineous unions and inbreeding coefficient with respect to demographic variable.

\begin{tabular}{|c|c|c|c|c|}
\hline Variable $^{*}$ & $\begin{array}{l}\text { Consanguineous } \\
\text { unions, No. (\%) }\end{array}$ & $\begin{array}{c}\text { Total } \\
\text { marriage, No. }\end{array}$ & $\begin{array}{l}\text { Odds } \\
\text { ratio\# }\end{array}$ & $\begin{array}{c}\text { Inbreeding } \\
\text { coefficient (ICF) }\end{array}$ \\
\hline \multicolumn{5}{|c|}{ Rural/urban residence } \\
\hline Rural & $444(65.5)$ & 678 & 1.37 & 0.0385 \\
\hline Urban & $489(58.0)$ & 843 & Reference & 0.0333 \\
\hline Total & $933(61.3)$ & 1,521 & & 0.0356 \\
\hline \multicolumn{5}{|l|}{ Literacy (subject) } \\
\hline Illiterate & $504(64.9)$ & 776 & 1.13 & 0.0379 \\
\hline Literate & $429(57.6)$ & 745 & Reference & 0.0333 \\
\hline \multicolumn{5}{|l|}{ Literacy (spouse) } \\
\hline Illiterate & $351(65.2)$ & 538 & 1.11 & 0.0383 \\
\hline Literate & $582(59.2)$ & 983 & Reference & 0.0342 \\
\hline \multicolumn{5}{|c|}{ Occupational categories (subject) } \\
\hline House-wife & $848(62.6)$ & 1355 & 1.59 & 0.0364 \\
\hline Working women & $85(51.2)$ & 166 & Reference & 0.0289 \\
\hline \multicolumn{5}{|c|}{ Occupational categories of spouse (spouse) } \\
\hline Manual jobs & $143(66.5)$ & 215 & 1.88 & 0.0392 \\
\hline Agriculture & $414(63.6)$ & 651 & 1.65 & 0.0370 \\
\hline Sales/business & $167(62.1)$ & 269 & 1.55 & 0.0360 \\
\hline Professional & $67(53.2)$ & 126 & 1.07 & 0.0298 \\
\hline Others & $83(57.2)$ & 145 & 1.27 & 0.0330 \\
\hline Services & $59(51.3)$ & 115 & Reference & 0.0303 \\
\hline \multicolumn{5}{|c|}{ Caste-system (spouse) } \\
\hline Kharal & $36(70.6)$ & 51 & 1.43 & 0.0426 \\
\hline Muslim-Rajput & 48 (69.6) & 69 & 1.41 & 0.0387 \\
\hline Jutt & $46(67.6)$ & 68 & 1.37 & 0.0345 \\
\hline Khokhar/Malik & $87(65.9)$ & 132 & 1.34 & 0.0405 \\
\hline Arain & $179(62.2)$ & 288 & 1.26 & 0.0368 \\
\hline Bhatti & $100(60.6)$ & 165 & 1.23 & 0.0346 \\
\hline Rajput & $89(57.1)$ & 156 & 1.16 & 0.0344 \\
\hline Others & $315(60.0)$ & 525 & 1.22 & 0.0345 \\
\hline Kamyanay & $33(49.3)$ & 67 & Reference & 0.0287 \\
\hline \multicolumn{5}{|l|}{ Family structure } \\
\hline Joint family & $528(68.1)$ & 775 & 1.80 & 0.0401 \\
\hline Nuclear family & $405(54.3)$ & 746 & Reference & 0.0310 \\
\hline \multicolumn{5}{|l|}{ Household type } \\
\hline Paternal & $830(62.8)$ & 1,321 & 1.59 & 0.0365 \\
\hline Maternal & $103(51.5)$ & 200 & Reference & 0.0301 \\
\hline \multicolumn{5}{|l|}{ Exchange marriage } \\
\hline Yes & $167(78.0)$ & 214 & 2.51 & 0.0467 \\
\hline No & $766(58.6)$ & 1307 & Reference & 0.0338 \\
\hline \multicolumn{5}{|c|}{ Subject's age at marriage (years) } \\
\hline Up to 20 & $315(56.5)$ & 558 & 1.38 & 0.0337 \\
\hline$>20$ & $618(64.2)$ & 963 & Reference & 0.0368 \\
\hline \multicolumn{5}{|c|}{ Matrimonial distance $(\mathrm{km})$} \\
\hline Up to 5 & $609(68.6)$ & 888 & 1.87 & 0.0405 \\
\hline$>5$ & $304(53.8)$ & 565 & Reference & 0.0304 \\
\hline \multicolumn{5}{|c|}{ Parental consanguinity } \\
\hline Yes & $272(73.5)$ & 370 & 1.76 & 0.0428 \\
\hline No & $214(61.1)$ & 350 & Reference & 0.0346 \\
\hline
\end{tabular}

*only statistically significant variables are reported

\# estimated through single factor logistic regression. 
Table-II: Significant predictors of consanguinity as depicted by multivariable logistic regression.

\begin{tabular}{lcccc}
\hline Variables in final model & Odds ratio & St. Err. & p-value & 95\% CI \\
\hline Age at marriage (subject) & 1.65 & 0.29 & 0.004 & $1.17-2.33$ \\
Caste-system (spouse) & 1.10 & 0.05 & 0.049 & $1.00-1.21$ \\
Family structure (joint) & 1.62 & 0.28 & 0.005 & $1.16-2.27$ \\
Matrimonial distance (up to 5 km) & 1.77 & 0.31 & 0.001 & $1.25-2.50$ \\
Parental consanguinity (yes) & 1.71 & 0.29 & 0.002 & $1.23-2.39$ \\
Exchange marriage (yes) & 2.42 & 0.65 & 0.001 & $1.43-4.09$ \\
_cons & 0.02 & 0.01 & 0.0001 & $0.00-0.08$ \\
\hline
\end{tabular}

having NCU (4.08 \pm 2.98 vs. $3.74 \pm 2.81$, respectively; $\mathrm{p}=0.007)$. A proportionately higher number of women with $\mathrm{CU}$ had a gap of $>24$ months in their first pregnancies compared to women with NCU $(p=0.03)$. Among the ever-pregnant women, mean live-births were significantly higher in women who had CU compared with the subjects having NCU $(3.62 \pm 2.68$ vs. $3.30 \pm 2.50$, respectively; $p=0.006)$. The differences were also statistically significant in the case of mean liveborn sons ( $1.90 \pm 1.64$ vs. $1.64 \pm 1.47$, respectively; $\mathrm{p}=0.0002)$, but not in live-born daughters $(p=0.406)$. Further, there were statistically no significant differences between the mothers with $\mathrm{CU}$ and NCU with respect to average mortalities (i.e., prenatal, postnatal and total).

\section{DISCUSSION}

Consanguinity was estimated to be $61.3 \%$ in the overall sample of Okara population, and the corresponding ICF was 0.0356 which is comparable to other populations of Pakistan; for instance, 0.0355 in RahimYar Khan and 0.0348 in Sargodha, and 0.0348 in Bhimber, AzadJammu Kashmir., ${ }^{2,13}$ Further analyses revealed that intracaste marriages were $90 \%$ in the total unions while their proportion ranged from $96 \%$ in Arain to $77 \%$ in Mirza caste-systems (data not shown). Although Okara is close to the metropolitan region of Lahore yet it has high level of consanguinity. This reflects that greater metropolitan regions are not exception of the CU. People remain intact to their cultural

Table-III: Subject fertility and live-births in consanguineous and non-consanguineous unions.

\begin{tabular}{|c|c|c|c|c|}
\hline Parameter & $\begin{array}{c}\text { Consanguineous } \\
\text { unions }\end{array}$ & $\begin{array}{c}\text { Non-consanguineous } \\
\text { unions }\end{array}$ & Total & $p$-value ${ }^{*}$ \\
\hline Average age (yrs) & $34.99 \pm 13.36$ & $35.16 \pm 13.31$ & $35.06 \pm 13.34$ & 0.67 \\
\hline \multicolumn{5}{|l|}{ Fertility } \\
\hline Ever pregnant women, No. (\%) & $872(60.8)$ & $562(39.2)$ & $1,434(94.3)$ & \\
\hline Fertility: pregnancy/women (mean $\pm S D)$ & $4.08 \pm 2.98$ & $3.74 \pm 2.81$ & $3.94 \pm 2.91$ & 0.007 \\
\hline \multicolumn{5}{|l|}{ Gap in first pregnancy } \\
\hline Up-to 24 months (\%) & 85.8 & 89.7 & 87.3 & 0.03 \\
\hline$>24$ months $(\%)$ & 14.2 & 10.3 & 12.7 & \\
\hline \multicolumn{5}{|l|}{ Live-births } \\
\hline Total live-births (No.) & 4,479 & 3,024 & 7,503 & \\
\hline Live-births/women (mean \pm SD) & $3.62 \pm 2.68$ & $3.30 \pm 2.50$ & $3.48 \pm 2.61$ & 0.006 \\
\hline Live-birth: sons (mean $\pm \mathrm{SD})$ & $1.90 \pm 1.64$ & $1.64 \pm 1.47$ & $1.79 \pm 1.58$ & 0.0002 \\
\hline Live-birth: daughters (mean $\pm S D$ ) & $1.72 \pm 1.61$ & $1.66 \pm 1.59$ & $1.69 \pm 1.60$ & 0.406 \\
\hline \multicolumn{5}{|l|}{ Mortalities } \\
\hline Data available on mothers (No.) & 1,239 & 915 & 2,154 & \\
\hline Mortality/women (mean $\pm S D)$ & $0.47 \pm 1.11$ & $0.44 \pm 1.17$ & $0.45 \pm 1.14$ & 0.528 \\
\hline Prenatal mortality (mean $\pm S D$ ) & $0.26 \pm 0.85$ & $0.27 \pm 0.93$ & $0.26 \pm 0.88$ & 0.658 \\
\hline Postnatal mortality (mean \pm SD) & $0.21 \pm 0.73$ & $0.16 \pm 0.74$ & $0.19 \pm 0.73$ & 0.169 \\
\hline \multicolumn{5}{|l|}{ Child morbidity ( $\leq 5$ years) } \\
\hline Mortality in sons, No. (\%) & $43(3.8)$ & $36(4.4)$ & 79 & $\mathrm{OR}=0.86$ \\
\hline Mortality in daughters, No. (\%) & $41(3.6)$ & $24(2.9)$ & 65 & $\mathrm{OR}=1.23$ \\
\hline
\end{tabular}

(*student T-test; statistical findings/significance did not differ when analyses were repeated through Mann-Whitney test and unpaired t-test with Welch's correction). 
values rather than accepting the norms and values of the metropolitan culture which is reported to have low consanguinity. ${ }^{14}$,

Multivariable analyses revealed that six variables were the significant predictors of consanguinity. For instance, with respect to family structure, the subject belonging to joint/extended family type had the higher occurrence of consanguinity. In joint family setup, CU are preferred because of the compatibility between subfamilies, i.e., similar tradition, education and economic levels, and among cousins living in the same environment. ${ }^{2,7}$ Consanguinity helps them to settle minor domestic conflicts and social and economic problems. ${ }^{14}$ Further, the rate of $\mathrm{CU}$ was significantly higher in subjects who had younger age at marriage. The analyses demonstrated that rate of consanguinity gradually declined as the age at marriage delayed. In joint family system, a large number of siblings reached to marriageable age., $, 7,14$ The parents prefer to marry their daughters among the relatives at her younger age because relative gives more respect to their daughters at a younger age. ${ }^{13-15} \mathrm{In}$ economically better-off families particularly in urban populations, the late age marriages may be commenced due to the time spent in completing education and career development which leads to a low choice of mates among the close-kins, thus resulting in outbreeding. ${ }^{5,15}$

The exchange marriages were observed to be positively associated with consanguinity both in univariate and multivariable analyses (OR: 1.33 and 2.62, respectively). Exchange marriages are customarily practiced in the rural areas of Punjab and Sindh provinces. ${ }^{14,16}$ Then, parental consanguinity was also observed to be a significant predictor of subject's consanguinity in the present study. This observation supports the notion that consanguinity is a family tradition that is practiced generations after generations. ${ }^{14,17}$

Our analyses showed that the average fertility was higher in women with $\mathrm{CU}$ compared to the women with NCU. Further, the average livebirths per woman were also significantly higher in subjects who had CU. Interestingly, a similar trend was also witnessed in RahimYar Khan, Pakistan, and several other populations of Asia and Africa. ${ }^{2,5}$ This phenomenon could be explained by the fact that owing to the marriages at younger age in $\mathrm{CU}$, the first birth occurs at an earlier age and the reproductive and fertile period of the women remains significantly longer. ${ }^{5}$ Further, several other fertility determinants are potentially confounding with CU which include, but not limited, to the duration of the marriage, low socio-economic status, rural residence and lower contraceptive use. ${ }^{4,18}$ However, $14 \%$ mothers with $\mathrm{CU}$ had a gap of $>24$ months in their first pregnancies compared to $10 \%$ mothers with NCU. This observation needs further investigations in extended data sets from other populations.

Nonetheless, the average male live-births were significantly higher in women with CU compared with the women with NCU (Table-III). The difference was, however, not significant in average female live-births. It has been previously suggested that consanguinity may affect the secondary sex ratio and the sex ratio decreases as consanguinity increases. ${ }^{19}$ However, sex ratio is also confounded by other direct or indirect variables like early age at marriage, paternal age, firstborn proportion and mother's age. ${ }^{20}$ Further studies are warranted to understand this phenomenon in cosmopolitan populations.

Strength and Limitaitons of the study: The strength of the present study are: first-hand data, large sample size, and coverage of large number of demographic variables. The potential limitations of this study could be that the high representation of subjects from urban areas and self-reported data on reproductive health. Further, this study does not document stillbirths, congenital anomalies, and maternal morbidity.

\section{CONCLUSION}

The overall rate of CU in Okara district is high like other inbred Pakistani populations. Here, higher mean fertility and mean live-births in subjects with $\mathrm{CU}$ are interesting findings and need further studies.

Acknowledgments: We highly appreciate the volunteer participation of subjects in the study.

Source of funding: HEC-Pakistan (Project\#20-3477).

Conflicts of interest: None declared.

\section{REFERENCES}

1. Ahmad M, Gilbert RI, Naqvi AU. Assortative mating for height in Pakistani arranged marriages. J Biosoc Sci. 1985;17(2):211-214. doi: 10.1017/s0021932000015662

2. Riaz HF, Mannan S, Malik S. Consanguinity and its sociobiological parameters in Rahim Yar Khan District, Southern Punjab, Pakistan. J Health Popul Nutr. 2016;35(1):14-19. doi: 10.1186/s41043-016-0049-x 
3. Bittles AH, Grant JC, Shami SA. Consanguinity as a determinant of reproductive behaviour and mortality in Pakistan. Int J Epidem. 1993;22(3):463-467. doi: 10.1093/ ije/22.3.463

4. Bittles AH, Grant JC, Sullivan SG, Hussain R. Does inbreeding lead to decreased human fertility? Ann Hum Bio. 2002;29:111-130. doi: 10.1080/03014460110075657

5. Bittles AH. Consanguinity, genetic drift, and genetic diseases in populations with reduced numbers of founders. In Speicher MR, Antonarakis SE, Motulsky AG. (eds) Vogel and Motulsky's Human Genetics. Berlin Heidelberg, Springer-Verlag. 2010;507-728.

6. Hashmi MA. Frequency of consanguinity and its effect on congenital malformation--a hospital based study. J Pak Med Assoc. 1997;47(3):75-78.

7. Zaman M. Marriage of Cousins: Congenital Diseases and People's Perception in Pakistan, a Public Health Challenge. J Pub Health Policy. 2010;31(3):381-383.

8. Hina S, Malik S. Pattern of consanguinity and inbreeding coefficient in Sargodha district, Punjab, Pakistan. J Biosoc Sci. 2015;47:803-811. doi: 10.1017/S0021932014000431

9. Ahmad B, Rehman AU, Malik S. Consanguinity and inbreeding coefficient in tribal Pashtuns inhabiting the turbulent and war-affected territory of Bajaur Agency, North-West Pakistan. J Biosoc Sci. 2016;48(1):113-128. doi: 10.1017/S0021932014000558

10. Cheema HA, Malik HS, Parkash A, Fayyaz Z. Spectrum of inherited metabolic disorders in pakistani children presenting at a tertiary care centre. J Coll Physicians Surg Pak. 2016;26(6):498-502.

11. Ahmad I, Rehman AU, Malik S. Determinants of consanguinity and inbreeding coefficient $\mathrm{F}$ in Dir Lower district, north-west Pakistan: a multivariate approach. Iran J Public Health. 2016;45(4):537-539.

12. PAP. Population Association of Pakistan. http://www.pap. org.pk/index.htm (Accessed Dec. 20, 2019)

13. Jabeen N, MalikS. Consanguinity and its socio-demographic differentials in District Bhimber, Azad Jammu Kashmir, Pakistan. J Health Popul Nutr. 2014;32(2),301-313.
14. Zaman M. Exchange Marriages in South Punjab, Pakistan: A Sociological Analysis of Kinship Structure, Agency, and Symbolic Culture. Frankfurt(M)/Berlin: Peter Lang Publisher. 2011.

15. Tufail M, Rehman AU, Malik S. Determinants of consanguinity and inbreeding coefficient in the multiethnic population of Mardan, Khyber Pakhtunkhwa, Pakistan. Asian Biomed. 2017;11(6):451-460. doi: 10.1515/ abm-2018-0022

16. Zaman M. Socio-cultural security, emotions and exchange marriages in a community. South Asia Res. 2008;28:285-298. doi: $10.1177 / 026272800802800303$

17. Zaman M, Shehzad H. Marriage and Family Conflicts in Pakistan: Indigenous Model of Conflict Management. J Gender Soc Issues. 2018;17(2):15-30.

18. Hussain R, Bittles AH. Consanguinity and differentials in age at marriage, contraceptive use and fertility in Pakistan. J Biosoc Sci. 1999;31:121-138. doi: 10.1017/s0021932099001212

19. Ansari NA, Sinha SP. Survey on the effects of inbreeding in two populations of Bihar. Indian J Med Res. 1978;68:295-299.

20. Ulizzi L, Zonta LA. Factors Affecting the Sex Ratio in Humans: Multivariate Analysis of the Italian Population. Hum Biol. 1995;67(1):59-67.

\section{Authors Contribution:}

SM: Conceived, designed and supervised the study; statistical analysis and manuscript writing

AN: Data collection and manuscript writing

MZ \& SM: Edited, reviewed and approval manuscript

SM is responsible and accountable for the accuracy and integrity of data. 